\title{
Methane plume over south Asia during the monsoon season: satellite observation and model simulation
}

\author{
X. Xiong ${ }^{1,2}$, S. Houweling ${ }^{3}$, J. Wei ${ }^{1,2}$, E. Maddy ${ }^{1,2}$, F. Sun ${ }^{1,2}$, and C. Barnet ${ }^{1}$ \\ ${ }^{1}$ NOAA/NESDIS/Center for Satellite Applications and Research, Camp Springs, Maryland, USA \\ ${ }^{2}$ Perot Systems Government Services, Fairfax, Virginia, USA \\ ${ }^{3}$ Netherlands Institute for Space Research, Utrecht, The Netherlands \\ Received: 18 April 2008 - Published in Atmos. Chem. Phys. Discuss.: 15 July 2008 \\ Revised: 21 November 2008 - Accepted: 21 November 2008 - Published: 2 February 2009
}

\begin{abstract}
Satellite retrievals of methane $\left(\mathrm{CH}_{4}\right)$ using the Atmospheric Infrared Sounder (AIRS) on the EOS/Aqua platform from 2003-2007 show a strong, plume-like enhancement of $\mathrm{CH}_{4}$ in the middle to upper troposphere over South Asia during July, August and September, with the maximum occurring in early September. Simulations using the global tracer model version 3 (TM3) also show similar seasonal enhancement of $\mathrm{CH}_{4}$ in the same region. The model results also suggest that this enhancement is associated with transport processes and local surface emissions, thus the observations of tropospheric $\mathrm{CH}_{4}$ during the monsoon season may be used to constrain the models for a better estimation of Asian $\mathrm{CH}_{4}$ sources. Further comparisons between the AIRS retrievals and the model simulations suggest a possible overestimate of emissions from rice paddies in Southeast Asia in the scenario with the global emissions from rice of $60 \mathrm{Tg} \mathrm{yr}^{-1}$. Moreover, the observed tropospheric $\mathrm{CH}_{4}$ enhancement from AIRS provides evidence for the strong transport of atmospheric pollutants from the lower to the upper troposphere in Asia during the monsoon season. The observed rapid disappearance of the local $\mathrm{CH}_{4}$ maximum in September may provide valuable information for studying the dissipation of the Tibetan anticyclone and the withdrawal of monsoon.
\end{abstract}

\section{Introduction}

As the most important greenhouse gas next to carbon dioxide $\left(\mathrm{CO}_{2}\right)$, methane $\left(\mathrm{CH}_{4}\right)$ is over 20 times more powerful at warming the atmosphere than $\mathrm{CO}_{2}$ by weight, and plays an important role in atmospheric chemistry (IPCC,

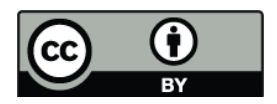

Correspondence to: X. Xiong (xiaozhen.xiong@noaa.gov)
2007). Therefore, understanding the emission sources of $\mathrm{CH}_{4}$ as well as its transport from the surface to the upper-troposphere/lower-stratosphere is essential for climate change study. This problem is particularly important over Southeast Asia as (1) the rice paddies found in this region are a major, seasonally varying $\mathrm{CH}_{4}$ emission source (Khalil et al., 1998; Huang et al., 2004), and (2) the deep convection over the Tibetan Plateau (TP) during the monsoon season occurs almost simultaneously with the seasonal high emission. By using satellite observation of carbon monoxide (CO) from the EOS Microwave Limb Sounder (MLS) and water vapor $\left(\mathrm{H}_{2} \mathrm{O}\right)$ from Tropical Rainfall-Measuring Missing satellite (TRMM), Fu et al. (2006) established that the TP provides the main pathway for cross-tropopause transport of water vapor and polluted air to the global stratosphere. Therefore, the transport of $\mathrm{CH}_{4}$ over Asia during the monsoon may constitute an important emission pathway transporting $\mathrm{CH}_{4}$ from lower to the upper atmosphere.

The Tibetan Plateau is located in the southwest of China and is the highest and biggest Plateau in the world, with an area of 2.5 million square kilometers. It is well known that the TP acts as a very strong heat source in summer and has a significant impact on the Asian Summer Monsoon (ASM). The intense convective activity generated at the TP and the large scale vertical motion associated with the ASM transport large amounts of sensible heat, moisture, chemical pollutants, as well as air with low ozone concentration from the near-surface layers to upper layers (Ye and $\mathrm{Wu}, 1998$; and references therein). For example, model simulations (Lawrence et al., 2003; Liu et al, 2003) suggested that deep convection associated with the ASM lifts the boundary layer pollutants from India, Southeast Asia, and southern China into the upper troposphere. A fraction of these can be transported westward by the tropical

Published by Copernicus Publications on behalf of the European Geosciences Union. 
easterly jet to the Middle East ( $\mathrm{Li}$ et al., 2001), and the Arabian Sea (Filipiak et al., 2005), thus influencing a part of Asia, Africa and Europe from June to September (Liu et al, 2003). Satellite measurements have provided some evidence for the transport of atmospheric components from the surface to the upper atmosphere. For example, enhancements of $\mathrm{CH}_{4}$, water vapor and nitrogen oxides near the tropopause over the monsoon region were observed from Halogen Occultation Experiment (HALOE) measurement on the Upper Atmosphere Research Satellite (UARS) (Park et al., 2004 and reference therein). Enhancement of $\mathrm{CO}$ was also observed over India and southern China from Measurements Of Pollution In The Troposphere (MOPITT) (Kar et al., 2004) and over the TP and southwest China from MLS (Li et al., 2005), and localized maxima of water vapor and minima of ozone associated with the monsoon were observed from the EOS/Aqua Atmospheric Infrared Sounder (AIRS) (Randel and Park, 2006).

In addition to the impact of large scale vertical motion associated with the ASM, the Tibetan anticyclone, which is one of the largest upper level anticyclones on Earth and is associated with the South Asia High, is also an important component for understanding the structure of atmospheric components in the monsoon region ( $\mathrm{Li}$ et al., 2005; Randel and Park, 2006). When the anthropogenic emissions from northeast India and southwest China are transported into the upper troposphere, they are entrained by the upper level Tibetan anticyclone (Li et al., 2005).

Previous satellite observations of $\mathrm{CH}_{4}$ by HALOE were made only near and above the tropopause. Measurements by the Michelson Interferometer for Passive Atmospheric Sounding (MIPAS) on Envisat (Payan et al., 2007) and by the Atmospheric Chemistry Experiment (ACE) (Nassar et al., 2005; De Mazière et al., 2007) are valid for a similar altitude region as HALOE. Nadir-viewing measurement of tropospheric $\mathrm{CH}_{4}$ has been made by the Interferometric Monitor for Greenhouse Gases (IMG) on board the Japanese Advanced Earth Observing Satellite (ADEOS) (Clerbaux et al., 2003) but there are only a few months' data available. So, to our knowledge, systematic measurements and analysis of the vertical variation of $\mathrm{CH}_{4}$ in the middle to upper troposphere over the TP have not been obtained. Because of this, our knowledge about the transport of $\mathrm{CH}_{4}$ in the monsoon region is limited. Moreover, there is a large uncertainty in the current estimation of $\mathrm{CH}_{4}$ emissions from rice paddies in Asia (Huang et al., 2004; IPCC, 2007). Observations by AIRS on EOS/Aqua have provided $\mathrm{CH}_{4}$ products in the middle to upper troposphere since September 2002 to present, and these products have been validated by Xiong et al. (2008). So, analysis of AIRS $\mathrm{CH}_{4}$ distribution and its seasonal variation may provide some new insights into $\mathrm{CH}_{4}$ emissions and transport in the monsoon region. As AIRS has the most sensitivity to $\mathrm{CH}_{4}$ at $150-300 \mathrm{hPa}$ in the tropics, which is just below the levels of the maximum confinement by Tibetan anticyclone at $\sim 200-100 \mathrm{hPa}$ (Randel and
Park, 2006), analysis of the vertical variation of AIRS $\mathrm{CH}_{4}$ in this region could provide information on the Tibetan anticyclone. For example, the tropospheric $\mathrm{CH}_{4}$ enhancement and its disappearance might be linked to the development and dissipation of the Tibetan anticyclone and the withdrawal of monsoon.

The aim of this paper is to explore the summer enhancement of $\mathrm{CH}_{4}$ in the middle to upper troposphere in South Asia using the AIRS $\mathrm{CH}_{4}$ product along with model simulation from an atmospheric transport model TM3 (Heimann and Korner, 2003; Houwelling et al., 2006). The seasonal variation of $\mathrm{CH}_{4}$ in this region is studied in further detail by comparing AIRS observations with model simulations after taking into account the averaging kernels characterizing the AIRS retrieval skill (Maddy and Barnet, 2008). These comparisons demonstrate that the AIRS $\mathrm{CH}_{4}$ product is in reasonable agreement with model calculations. Further evidence is provided from the in-situ measurement of the $\mathrm{CH}_{4}$ seasonal cycle for five sites at the periphery of the Tibetan Plateau. To better understand the impact of dynamic transport on the formation of a $\mathrm{CH}_{4}$ plume, the monthly wind fields from National Oceanic and Atmospheric Administration (NOAA), National Centers for Environmental Prediction (NCEP) analysis data are also analyzed. One more experiment of model simulation is carried out to investigate the sensitivity of the enhancement of tropospheric $\mathrm{CH}_{4}$ to surface emissions in Southeast Asia. If this sensitivity is significantly larger than the uncertainties in model simulations and satellite retrievals, we can expect that the tropospheric $\mathrm{CH}_{4}$ from the space-borne observations during the monsoon season might be used as an additional constraint to the models, as compared to the constraint that uses the ground-based measurement of $\mathrm{CH}_{4}$ concentration in most "top-down" approaches, for the estimation of Asian $\mathrm{CH}_{4}$ sources.

\section{Data and method}

AIRS was launched into the polar orbit (1:30 p.m., ascending node) on National Aeronautics and Space Administration (NASA) EOS/Aqua platform in May 2002. It has 2378 channels covering from 649-1136, 1217-1613 and $2169-2674 \mathrm{~cm}^{-1}$ at high spectral resolution $(\lambda / \Delta \lambda=1200$, $\sim 0.5 \mathrm{~cm}^{-1}$ ) (Aumann et al., 2003), and the noise equivalent change in temperature $(\mathrm{NE} \Delta T)$, at $250 \mathrm{~K}$ reference temperature, ranges from $0.14 \mathrm{~K}$ in the critical $4.2 \mu \mathrm{m}$ lower tropospheric sounding wavelengths to $0.35 \mathrm{~K}$ in the $15 \mu \mathrm{m}$ upper tropospheric sounding region. The spatial resolution of AIRS is $13.5 \mathrm{~km}$ at nadir, and in a $24-\mathrm{h}$ period AIRS nominally acquires measurements over the complete globe twice daily. In order to retrieve $\mathrm{CH}_{4}$ in both clear and partially cloudy scenes, 9 AIRS pixels in the footprint of an Advanced Microwave Sounding Unit (AMSU) pixel are used to obtain the cloud-cleared radiance (CCR) in this regard. The CCR product is then used for sounding retrievals with the spatial 
resolution of about $45 \mathrm{~km}$. The version 5 of AIRS product retrieval software has been put into operation at NASA Goddard Earth Sciences Data and Information Services Center (DISC), and these data are currently available at the Goddard DISC (http://disc.gsfc.nasa.gov/AIRS/overview). An "off-line" version of the AIRS product is run at NOAA National Environmental Satellite, Data, and Information Service (NESDIS), Center for Satellite Application and Research, where the data are thinned to a $3^{\circ} \times 3^{\circ}$ spatial grid, and the retrieved $\mathrm{CH}_{4}$ data are used in this paper. As detailed by Xiong et al. (2008), over 70 AIRS channels near $7.6 \mu \mathrm{m}$ are used for the $\mathrm{CH}_{4}$ retrieval, and the atmospheric temperature profile, water profile, surface temperature and surface emissivity required as inputs are derived from other AIRS channels. With these data along with a first-guess profile of $\mathrm{CH}_{4}$ as inputs to the forward model (Strow et al., 2003), we can compute the upwelling radiance. The difference between the computed radiance and the cloud cleared radiance, $\Delta R$, can be used to calculate a change to the $\mathrm{CH}_{4}$ profile, $\Delta x$, as follows:

$\Delta R_{n}=S_{n, L} \times \Delta X_{L}+\varepsilon$

where $R_{n}$ is the cloud cleared radiance (measured), and $\Delta R_{n}$ is $R_{n}$ minus the calculated radiance in channel $n, \varepsilon$ represents the noise, $S_{n, L}$ is the sensitivity of radiance in channel $n$ to the change of $\mathrm{CH}_{4}$ for layer $L$, and $\Delta X_{L}$ is the difference of $\mathrm{CH}_{4}$ from the first-guess at layer $L$ that needs to be derived. Equation (1) can be solved by performing singular value decomposition (SVD) on the covariance of the sensitivity matrix, weighted by an inverse of the estimates of the precision and accuracy of the radiative transfer model (RTM) plus the errors and noise in the measurements. Damping the least significant eigenfunctions of the SVD to constrain the solution, the change in $\mathrm{CH}_{4}$ is then written as:

$\Delta X_{L}=U \times \frac{1}{\lambda+\Delta \lambda} \times U^{T} \times S^{T} \times W \times \Delta R_{n}$

where $U$ is the eigenvector from the SVD, $W$ is the inverse error matrix, and ${ }^{T}$ represents the transpose operator. $\Delta \lambda$ is the damping variable proportional to the eigenvalue $\lambda$ as defined in Eq. (38) of Susskind et al. (2003). The eigenfunctions are updated at each iteration of the retrieval with an ongoing information content analysis (Susskind et al., 2003). This retrieval methodology minimizes the dependence of the solution to the first-guess field and the first-guess error characteristics, and relies exclusively on the signal to noise of the observation to indicate the degree to which the information contained in the radiances should be believed.

Validation using in-situ aircraft observations showed the bias of the retrieved $\mathrm{CH}_{4}$ profiles is approximately $-1.4 \sim+0.1 \%$ and its $\mathrm{rms}$ difference is about $0.5-1.6 \%$ (Xiong et al., 2008). In general, the information content of AIRS measurements of $\mathrm{CH}_{4}$ near the tropics is larger than in other regions, so it is easier for AIRS to observe the variation of $\mathrm{CH}_{4}$ near the tropics than that in high latitude regions according to the validation (Xiong et al., 2008). Due to the lack of in-situ observation of $\mathrm{CH}_{4}$ profile over the TP, validation to AIRS $\mathrm{CH}_{4}$ product in the region studied in this paper can not be made. The uncertainties in the AIRS retrievals of $\mathrm{CH}_{4}$ include (1) the errors in atmospheric temperature and water moisture profiles, surface temperature and emissivity (derived from other channels of AIRS) over high terrain like the TP (these errors over high terrain may be relatively larger than in most other regions), (2) the errors in the RTM (Strow et al., 2003), including the spectroscopy of $\mathrm{CH}_{4}$, and (3) the error in cloud clearing, which may be larger than normal as more clouds have been observed forming over the TP region (Taniguchi and Koike, 2008). The increase of moisture imported by ASM to the TP region pushes the most sensitive region of AIRS $\mathrm{CH}_{4}$ channels to higher altitudes, which also leads to some moisture-dependent artifact in the seasonal variation of the retrieved $\mathrm{CH}_{4}$ in a given layer (Xiong et al., 2008). These uncertainties may hamper the accurate comparison of satellite data with model, but the analysis of AIRS $\mathrm{CH}_{4}$ distribution and its seasonal change allows us to make a qualitative assessment of the impact on the transport and surface emissions during the monsoon season. To reduce the uncertainty in the analysis of AIRS $\mathrm{CH}_{4}$ data, we rejected the profiles with an obvious oscillation outside of the variation range of $\mathrm{CH}_{4}$ in the troposphere, or when the degree of freedom is lower than 0.7 .

The global $\mathrm{CH}_{4}$ concentration from transport model simulations, as reported by Houweling et al. (2006), have been obtained using a source scenario (S3) as input to the atmospheric transport model TM3 (Heimann and Korner, 2003). This scenario, S3, includes direct plant emissions and the global $\mathrm{CH}_{4}$ emissions from rice of $60 \mathrm{Tg} \mathrm{yr}^{-1}$ (see Table 1 in Houweling et al., 2006). The $60 \mathrm{Tg} \mathrm{yr}^{-1}$ emissions from rice may be overestimated for Southeast Asia based upon comparisons with measurements from the surface and SCanning Imaging Absorption spectroMeter for Atmospheric CHartographY (SCIAMACHY) (Frankenberg et al., 2005). Model simulations have been performed on $3.75 \times 5$ degree horizontal resolution (latitude $\times$ longitude) for the period 2001-2004 with meteorological fields derived from the NCEP reanalysis (Kalnay et al., 1996). To test the sensitivity of the tropospheric $\mathrm{CH}_{4}$ to surface emissions, we re-ran the model (denoted as the "2nd run") by changing the surface emissions only. Since the variation of $\mathrm{CH}_{4}$ emissions from rice agriculture can be large and it is difficult to estimate the regional $\mathrm{CH}_{4}$ emissions accurately, the estimated emissions given by different researchers range from 31 to $112 \mathrm{Tg} \mathrm{yr}^{-1}$ (IPCC, 2007 and references therein). So, for simplification, in the 2nd run we assumed an increase of $\mathrm{CH}_{4}$ emissions by $50 \%$ in Southeast Asia in the region between $67.5^{\circ} \mathrm{E}-127.5^{\circ} \mathrm{E}$ and $3.83^{\circ} \mathrm{N}-42.13^{\circ} \mathrm{N}$ (denoted as Region I, the large box in the lower bottom panel of Fig. 1). The area with significant $\mathrm{CH}_{4}$ enhancement, considered in this paper, is chosen in the region between $80^{\circ} \mathrm{E}-110^{\circ} \mathrm{E}$ and $20^{\circ} \mathrm{N}-35^{\circ} \mathrm{N}$ (denoted as Region II, the small box in Fig. 1). The area of 


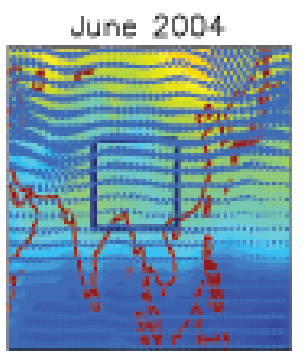

TM3

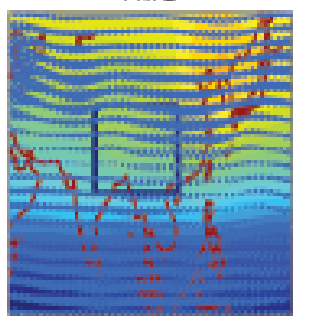

July 2004

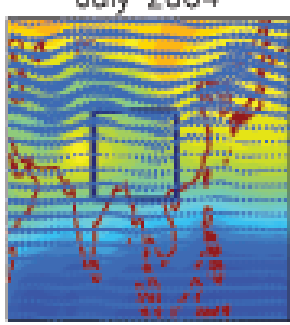

TM3

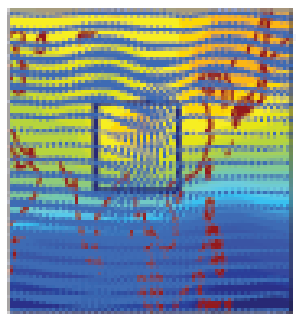

August 2004

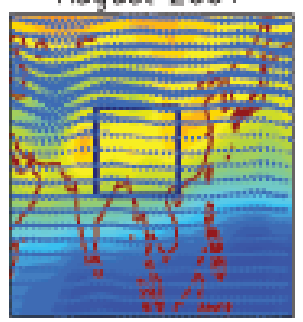

TM3

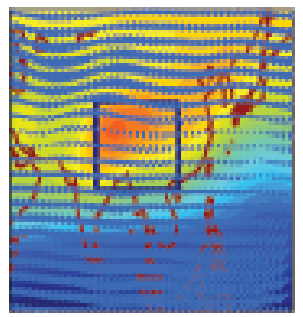

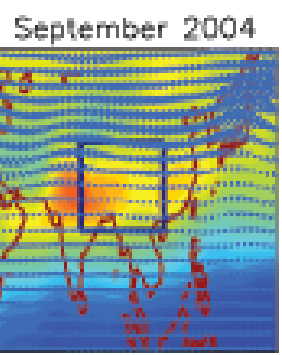

TM3

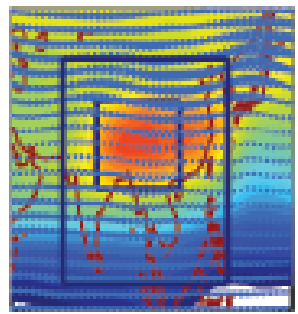

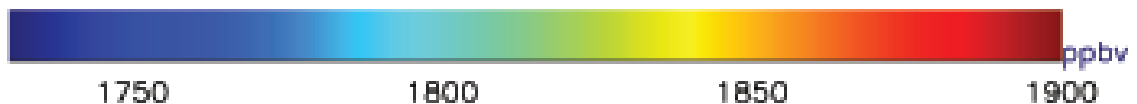

1750

1800

1850

1900

Fig. 1. Spatial variation of monthly mean $\mathrm{CH}_{4}$ at $300 \mathrm{hPa}$ from June to September 2004 in Southeast Asia observed from AIRS observation (top) and model simulation using the TM3 (bottom). Significant enhancement of $\mathrm{CH}_{4}$ is evident in August and September. The wind fields at $300 \mathrm{hPa}$ (top) and $150 \mathrm{hPa}$ (bottom) are shown, respectively. The large box denotes Region I and the small box denotes Region II.

Table 1. Summary of Stations at the Periphery of the Tibetan Plateau and the Data Used.

\begin{tabular}{lllll}
\hline Code & Location & Latitude, Longitude & Elevation $(\mathrm{m})$ & Period \\
\hline BKT & Bukit Koto Tabang, Indonesia & $0^{\circ} 12^{\prime} \mathrm{N}, 100^{\circ} 19^{\prime} \mathrm{E}$ & 864.5 & $2004-2005$ \\
WLG & Mt. Waliguan, China & $36^{\circ} 29^{\prime} \mathrm{N}, 100^{\circ} 90^{\prime} \mathrm{E}$ & 3810 & $1992-2004$ \\
UUM & Ulaan Uul, Mongolia & $44^{\circ} 27^{\prime} \mathrm{N}, 111^{\circ} 5^{\prime} \mathrm{E}$ & 914 & $1992-2005$ \\
KZD & Sary Taukum, Kazakhstan & $44^{\circ} 27^{\prime} \mathrm{N}, 75^{\circ} 34^{\prime} \mathrm{E}$ & 412 & $1998-2005$ \\
KZM & Plateau Assy, Kazakhstan & $43^{\circ} 15^{\prime} \mathrm{N}, 77^{\circ} 52^{\prime} \mathrm{E}$ & 2519 & $1998-2005$ \\
\hline
\end{tabular}

Region I is set to be much larger than Region II is because the surface emissions from all areas of Region I could possibly contribute to the formation of $\mathrm{CH}_{4}$ plume in Region II. The wind fields plotted in this paper are downloaded from NCEP/NOAA analysis data (http://www.cdc.noaa.gov/cdc/ data.ncep.reanalysis.html).

Since there are no in-situ observations of $\mathrm{CH}_{4}$ in the middle to upper troposphere in southern Asia, we analyzed the ground-based measurements of $\mathrm{CH}_{4}$ from five stations of the NOAA flask network at the periphery of the TP. The analysis of the $\mathrm{CH}_{4}$ seasonal cycle from these stations, particularly the difference of seasonal cycle in two stations that are close to each other but in different altitudes, may provide some information about the transport and emissions. A summary of the location, elevation and the period of measurement used for these five stations is given in Table 1. Data of $\mathrm{CH}_{4}$ for these five stations are downloaded from (ftp://gaw.kishou.go. jp/pub/data/data_up_to_December2006/ch4/).

Due to the change of information content inherent in the infrared observation, which is related to but not limited to the atmospheric temperature-moisture profiles, a good comparison of the satellite observation with model simulation requires the use of averaging kernels to convolve the model data as below (Rodgers, 2000):

$\hat{x} \approx A x+(I-A) x_{a}$

where $\hat{x}$ is the convolved $\mathrm{CH}_{4}$ mixing ratio profile, $x$ is the profile from the transport model, and $x_{a}$ is the first-guess profile ("a priori"), which is a function of latitude and pressure but does not vary with time and longitude (Xiong et al., 
2008). $I$ is the identity matrix, and $A$ is the averaging kernel matrix. In real application for $\operatorname{AIRS}, \log (x), \log \left(x_{a}\right)$, and $\log \hat{x}$ are used instead of $x, x_{a}$, and $\hat{x}$ in Eq. (3). Differences between AIRS observations and the model convolved data will reflect the biases between satellite observation and the model simulation (as a reference) after taking into account the retrieval smoothing associated with the variation of information content in satellite observation. Unless otherwise stated, the model data referred in this paper are data that have been convolved with AIRS averaging kernels.

\section{Results and discussion}

3.1 Spatial distribution of tropospheric $\mathrm{CH}_{4}$ over Southeast Asia from AIRS observations and model simulations

A significant increase of $\mathrm{CH}_{4}$ in the middle to upper troposphere in Southeast Asia was observed by AIRS in July, August and September for each year from 2003-2007. The monthly mean distribution of $\mathrm{CH}_{4}$ at $300 \mathrm{hPa}$ observed by AIRS in 2004 and its counter part from model simulation is illustrated in Fig. 1. The model data are convolved using the corresponding monthly mean averaging kernels. The monthly horizontal wind fields at $300 \mathrm{hPa}$ are overlayd with AIRS observations in the top panels of Fig. 1, and the monthly horizontal winds at $150 \mathrm{hPa}$ are plotted in the bottom panels in order to demonstrate the strength and location of the Tibetan anticyclone. In July, AIRS shows a significant enhancement of $\mathrm{CH}_{4}$ over Northern India. In August, both the AIRS observation and model simulation show a strong enhancement in the upper half the Region II. The maximum occurs in September with the area of significant $\mathrm{CH}_{4}$ enhancement extending slightly southward to the lower part of Region II. Overall, the location of the $\mathrm{CH}_{4}$ maximum, as observed by AIRS, is shifted westward compared with that of the model simulation. Particularly, in Northern India, higher $\mathrm{CH}_{4}$ is observed by AIRS than that from model simulation, while in the southeast of China lower $\mathrm{CH}_{4}$ is observed by AIRS than that from model simulation. A recent study by Taniguchi and Koike (2008) indicates that there is more cloud activity over North India during JuneJuly than middle May to June. Some similarity between the location of the $\mathrm{CH}_{4}$ maximum with the location of low Outgoing Longwave Radiation (OLR) (Fig. 13b in Taniguchi and Koike, 2008) indicates that uncertainties in the CCRs used in the AIRS $\mathrm{CH}_{4}$ retrieval algorithm may be related to the retrieved spatial structure in this region. The higher $\mathrm{CH}_{4}$, seen in the model simulation over southeast China, may be associated with the possible overestimate of $\mathrm{CH}_{4}$ emission in the model. Park et al. (2004), using HALOE measurements, also reported a $\mathrm{CH}_{4}$ maximum at $136 \mathrm{hPa}$ with its location toward the west of that obtained from simulations by the Model for Ozone and Related Chemical Tracers (MOZART) (see Park et al., 2004; Fig. 3). This consistency between HALOE (at a higher altitude) and AIRS observations, as compared to the models (although they are two different models), may indicate some other possible uncertainties exist in the models as well.

The formation of the $\mathrm{CH}_{4}$ plume is closely related with the circulation, which can be seen from the wind fields in Fig. 1. To better illustrate the relation of the $\mathrm{CH}_{4}$ plume with circulation, we also compared the monthly change of $\mathrm{CH}_{4}$ mixing ratio at $300 \mathrm{hPa}$ between AIRS observations and model simulations (Fig. 2). The monthly change percentage is defined as $\mathrm{CH}_{4}$ mixing ratio in the present month divided by $\mathrm{CH}_{4}$ in the previous month, that is, $100 \times\left(\mathrm{CH}_{4}\right.$-present $/ \mathrm{CH}_{4}$-previous $)$ -100 . The wind fields at $850 \mathrm{hPa}$ from June to September are plotted in order to illustrate the dynamic transport in the lower troposphere. A careful examination of the wind fields at $850 \mathrm{hPa}$ and $150 \mathrm{hPa}$ shows that there is strong convergence around the TP (upper part of Region II) in July and August, and a strong anticyclone over the TP in August and September. The center of the anticyclone moves southward slightly from around $30^{\circ} \mathrm{N}$ in August to $25^{\circ} \mathrm{N}$ in September. From June to July, model simulations show that the most significant increase occurs in the center of Region II, but AIRS observations show the area with significant increase is shifted northwestward in Region II with a larger enhancement west of Region II. Moreover, observations from AIRS suggest the transport is mainly from the Middle East in the westerly jet, but this transport is relatively smaller in the model simulation. Instead, the model simulations show a stronger transport northwestward across the Indian Subcontinent, which is likely associated with the propagation of the monsoon from June to early July.

From July to August, the area with a significant increase from the model is more westward of that from AIRS. Model simulation also show the transport is mainly from India as the monsoon moves to a higher altitude in the north of the Indian subcontinent, and the transport from northeast China along the northern branch of Tibetan anticyclone is relatively small. However, the AIRS observations suggest that the strong convergence around the TP is the driver for the enhancement in the center of Region II.

From August to September the area with a significant increase in the model is eastward of that from AIRS. Model simulations also show the most significant increase of $\mathrm{CH}_{4}$ occurs in the southeast of the TP, which is likely to be associated with the transport of $\mathrm{CH}_{4}$ from Southeast China along the southern slope of the TP in the easterly jet. But the AIRS observations show that the most significant enhancement occurs in Northern India, and the impact of transport from southeast China is much smaller than that from the model simulations.

The differences between the AIRS observations and model simulations, in terms of both the $\mathrm{CH}_{4}$ in September (Fig. 1) and the $\mathrm{CH}_{4}$ change from August to September (Fig. 2), lead us to believe that the assumed $\mathrm{CH}_{4}$ emission from rice in the model $\left(60 \mathrm{Tg} \mathrm{yr}^{-1}\right)$ is possibly an overestimate. Our result is 


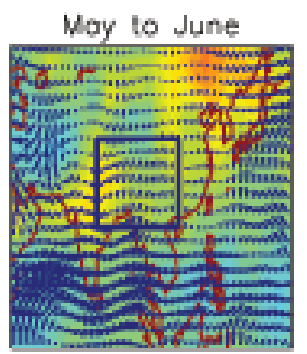

TM3

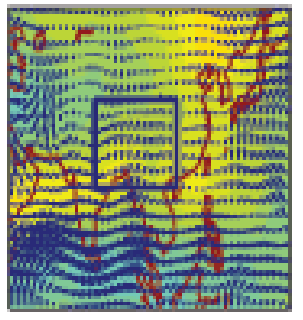

June to July

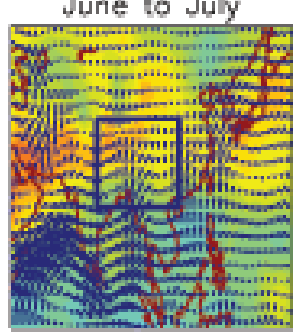

TM3

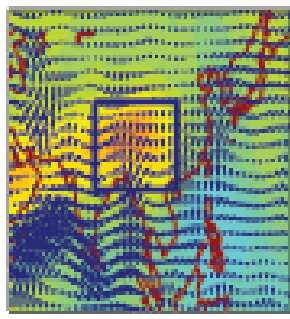

July to Auqust

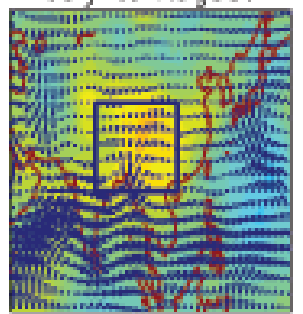

TM3

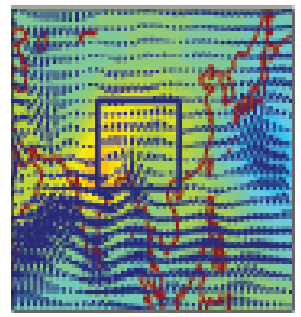

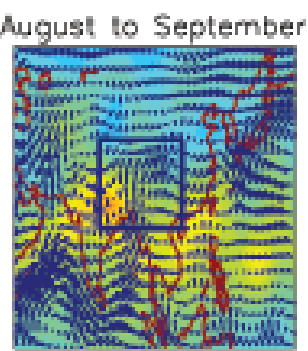

TM3

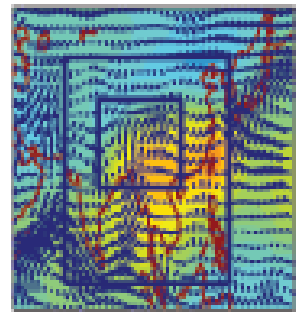

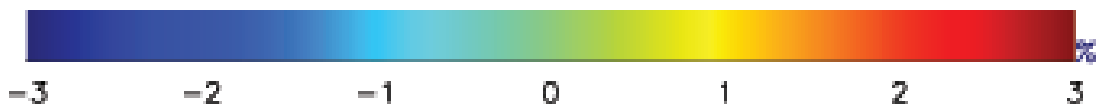

Fig. 2. Spatial variation of the monthly changed $\mathrm{CH}_{4}$ at $300 \mathrm{hPa}$, defined as the percentage change of $\mathrm{CH}_{4}$ mixing ratio in one month compared to its previous month, observed by AIRS (top) and model simulation (bottom). The wind fields at $850 \mathrm{hPa}$ are shown.

consistent with many recent studies that show the emission converges on the lower end of the range given by IPCC (IPCC, 2007; Frankenberg et al., 2005). The $\mathrm{CH}_{4}$ emissions from rice are likely to have declined in recent years, especially in China where agricultural practices have shifted to intermittent flooding and a greater reliance on nitrogen fertilizers (Li et al., 2002; Khalil and Shearer, 2006).

Due to the uncertainties in both satellite retrievals and model simulations, this comparison does not attempt to assess the absolute accuracy of either the AIRS product or the model simulations with regards to the $\mathrm{CH}_{4}$ plume in Southeast Asia in the summer. On the contrary, the aim of our comparison between AIRS and model is to demonstrate the existence of discrepancies between them, and call for more study toward using the AIRS observations in conjunction with the model to better quantify the Asian $\mathrm{CH}_{4}$ sources and sinks in summer. Further validation of the AIRS product, as well as the improvement to AIRS retrieval algorithm and quality control, will be the on-going efforts in the future.

\subsection{Seasonal variation of $\mathrm{CH}_{4}$ plume}

Using the AIRS observations from August 2003 to December 2007, we computed the mean $\mathrm{CH}_{4}$ profile averaged in Region II. To better illustrate the information content of the AIRS retrieved seasonal variation of $\mathrm{CH}_{4}$, only the mean profiles from ascending node (daytime) during May to October
2004 are plotted in Fig. 3. A significant increase of $\mathrm{CH}_{4}$ at $150-300 \mathrm{hPa}$ is evident beginning in early July and peaking around 5 September 2004. The most significant change of $\mathrm{CH}_{4}$ occurs within a pressure layer between $150-300 \mathrm{hPa}$ as marked by the box. This layer corresponds to the most sensitive regions of AIRS measurements. As the sensitivity in the lower troposphere is small, AIRS retrieved profiles tend to stick to the first guess and thus the seasonal variation in lower troposphere can not be observed directly by AIRS.

A comparison of the seasonal variation of $\mathrm{CH}_{4}$ anomalies (relative to the August 2003 to December 2007 mean) in Region II from AIRS observations and model simulations is shown in Fig. 4. This comparison of the seasonal cycle helps to reduce any bias between the AIRS observation and model simulation. Because the model data are not available for 2005 to 2007, we used instead the 2004 model data but convolved by the averaging kernels of each AIRS observation. The seasonal change of about $100 \mathrm{ppb}$ repeats every year, and the annual difference in the $\mathrm{CH}_{4}$ maxima as well as its occurrence time are small. On average, the minimum of $\mathrm{CH}_{4}$ occurs around 11 June, and the maximum occurs around 7 September, with a standard deviation of about 1 week. As indicated by Fasullo and Webster (2003), the mean onset date of the ASM is 4 June (with a standard deviation of about 7.4 days) and mean withdrawal date is 7 September (with a standard deviation of about 11 days ). So, these dates of $\mathrm{CH}_{4}$ plume occurrence and disappearance might be 


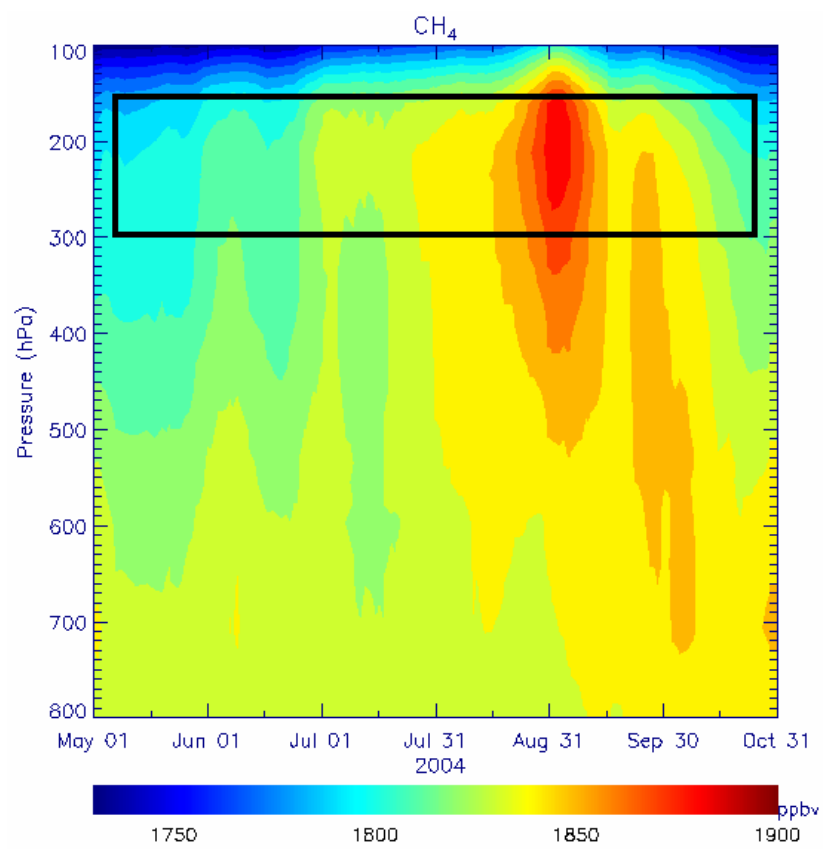

Fig. 3. Time-pressure cross section of AIRS $\mathrm{CH}_{4}$ averaged in $\mathrm{Re}-$ gion II. Data is from the ascending node (13:30 LST). Significant enhancement of $\mathrm{CH}_{4}$ at the middle to upper troposphere is evident, with the maximum occurring in early September. The most sensitive region of AIRS to $\mathrm{CH}_{4}$ at $150-300 \mathrm{hPa}$ is highlighted in the box.

closely related with the ASM. The mixing ratio of $\mathrm{CH}_{4}$ over South Asia decreases from its maximum quickly to the level in early June in about 10-12 days. The rapid decrease of $\mathrm{CH}_{4}$ in September, in contrast to its slow increase from June, is similar to the progress of the monsoon. The similarity of $\mathrm{CH}_{4}$ variation with the onset and the withdrawal of the ASM implies that the dynamic transport associated with the ASM has an important impact on the formation of the $\mathrm{CH}_{4}$ plume. As a consequence, the time for the disappearance of the $\mathrm{CH}_{4}$ maximum observed from satellite may be used as an index to mark the withdrawal of the ASM.

Figure 4 could also be plotted with the oceanic or continental background removed, which may give us some information of the months of maximum emissions, rather than a cycle heavily influenced by $\mathrm{OH}$ activity. We tried to use the retrieved $\mathrm{CH}_{4}$ over the ocean and the zonal average as the background, but in either way we did not notice any significant change to Fig. 4. This analysis further confirms (1) the formation of the $\mathrm{CH}_{4}$ plume begins in early July and peaks around the end of August to early September in South Asia, and (2) this $\mathrm{CH}_{4}$ enhancement is associated with both the transport processes and the local surface emissions. However, it is hard to identify the months of maximum emissions as the impact of emission coexists with the impact of transport. The dependence of the $\mathrm{CH}_{4}$ plume on the emission can be found from the sensitivity study using the model in Sect. 3.3.

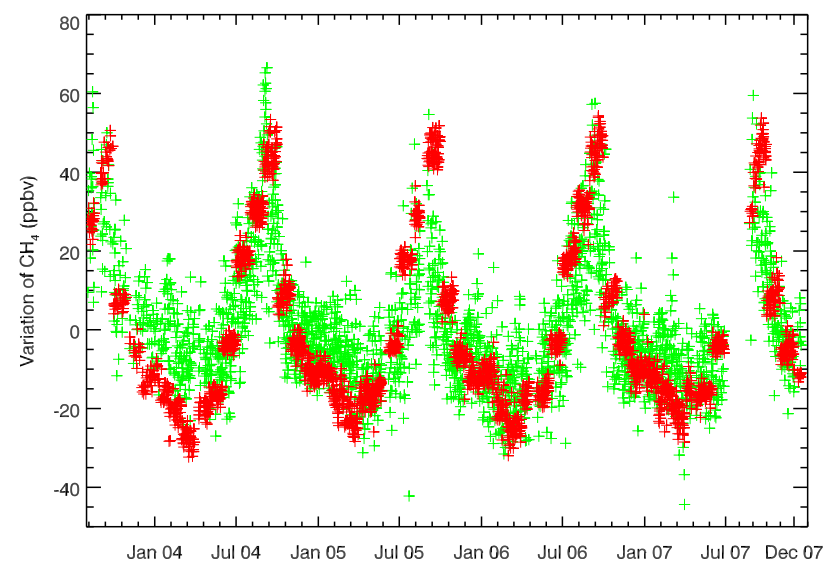

Fig. 4. Seasonal variation of $\mathrm{CH}_{4}$ at $300 \mathrm{hPa}$ averaged in Region II from August 2003 to December 2007. Green is AIRS observations. Red is the model data in 2004 convolved with averaging kernels from each AIRS retrieval. The magnitude of $\mathrm{CH}_{4}$ increase is up to $100 \mathrm{ppbv}$ with little annual difference.

Using the $\mathrm{CH}_{4}$ measurements from five stations of the NOAA flask network at the periphery of the TP (Table 1), we analyzed the mean annual $\mathrm{CH}_{4}$ cycle at each station (Fig. 5). The mean annual $\mathrm{CH}_{4}$ cycle was derived from the monthly mean values by subtracting annual mean for each year and then averaging all the values in each month (independent of year). As shown in Fig. 5, the $\mathrm{CH}_{4}$ annual seasonal cycle observed at BKT (Indonesia) and UUM (Mongolia) reach the minimum in summer and the maximum in late fall to midwinter. However, at WLG (Mt. Waliguan, China, $3810 \mathrm{~m}$ ) there is only a very weak seasonal cycle but with a slight maximum in summer. For the observations at KZD and KZM, two stations close to each other but with a difference in the elevation, their seasonal cycles are quite different (lower right panel of Fig. 5). In the boundary layer (from station KZD, $412 \mathrm{~m}$ ) the $\mathrm{CH}_{4}$ reaches the minimum in summer, but in the free atmosphere (from station KZM, 2519 m) the $\mathrm{CH}_{4}$ has a weak seasonal cycle with a slight maximum in July, August and September. The summer $\mathrm{CH}_{4}$ increase in the free atmosphere, as observed at both WLG and KZM, is similar to AIRS observations and model simulations. Although the elevations of these two sites are much lower than the altitude where AIRS has the most sensitivity, this similarity in the observed summer increase of $\mathrm{CH}_{4}$ provides evidence to partially support why the AIRS observations are reasonable.

From the analysis of 10-years' observation of $\mathrm{CH}_{4}$ in western China, Zhou et al. (2004) pointed out that the summer increase at Waliguan was subject to a $\mathrm{CH}_{4}$ source, likely attributed to ruminants at the high plateau meadow in summer, as well as subsequent air mass transport from surrounding regions, especially prevailing eastern winds in summer. However, as reported by Li et al. (2005), MLS and MOPITT data showed the $\mathrm{CO}$ maximum occurring during 25 August to 6 

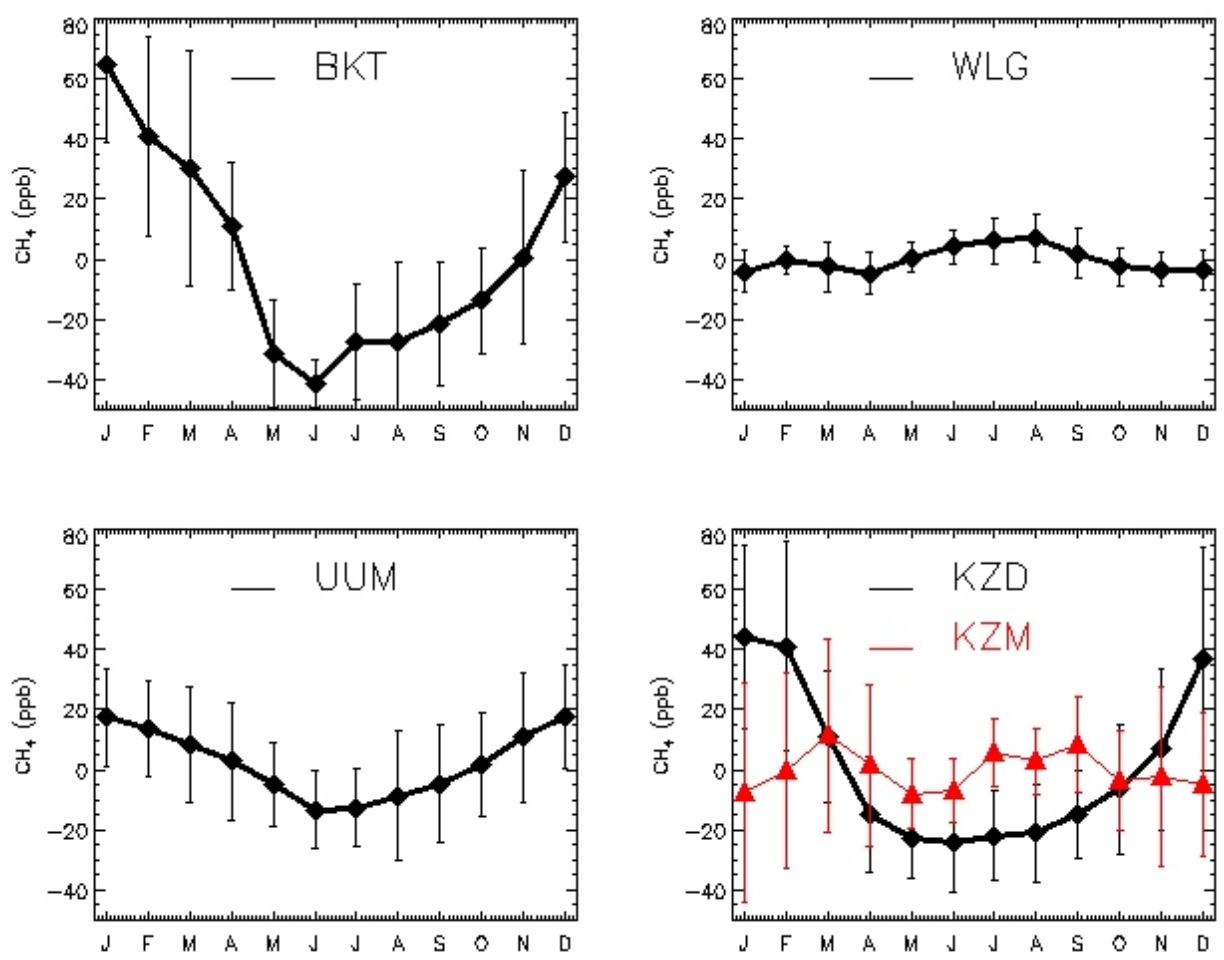

Fig. 5. Mean seasonal $\mathrm{CH}_{4}$ cycle for stations BKT, WLG, UUM, KZD and KZM (Table 1) at the periphery of the Tibetan Plateau. The thick lines are derived by $\mathrm{CH}_{4}$ data for each month, with standard deviation as error bar.

September 2004 over the TP and South China. This temporal consistency of the $\mathrm{CO}$ and $\mathrm{CH}_{4}$ maxima, as well as the local maximum of water vapor and the minimum of ozone, implies that the dynamic transport is likely to be the most important factor driving the formation of the local maxima of water vapor, $\mathrm{CH}_{4}$ and $\mathrm{CO}$.

It is hard to know the relationship between the maximum of $\mathrm{CH}_{4}$ in the middle to upper troposphere and the maximum of $\mathrm{CH}_{4}$ emission from rice paddies in Asia. Although a lot of field observations of $\mathrm{CH}_{4}$ emission from rice paddies have been made under a variety of soils, climates and agricultural practices in Asia (Khalil et al., 1998; Huang et al., 2004), precise estimates of $\mathrm{CH}_{4}$ emissions from regional or global rice paddies via up-scaling have been difficult due to large differences in spatial and temporal variability in climate, soils and agricultural practices (Huang et al., 2004). While a large range of emissions was given by the IPCC (IPCC, 2007 and references therein), both the monthly total, as well as the seasonal maximum, of Asian $\mathrm{CH}_{4}$ emissions are still not well known. Moreover, the contributions of other emission sources over the TP, such as the emissions from wetlands on the TP (Jin et al., 1999) and the emissions from grass meadows (Cao et al., 2008), need to be taken into account. Recent observation found the $\mathrm{CH}_{4}$ emission from grasses peaks in summers, whereas shrubs are more active at consuming methane in winter (Cao et al., 2008).
3.3 The pressure level dependence of the $\mathrm{CH}_{4}$ enhancement and its relation with the anticyclone

From the model calculations, we worked out the relative increase of $\mathrm{CH}_{4}$ averaged in Region II from July to October against the June average. As shown in Fig. 6, the seasonal trend in different pressure levels is similar; however, the magnitude of the ratio of $\mathrm{CH}_{4}$ in September to that in June, which we will assume to represent the "plume strength", varies greatly with altitude. Below $300 \mathrm{hPa}$ the plume strength increases with altitude, that is, it increases from $2.7 \%$ at $600 \mathrm{hPa}$ to $3.1 \%$ at $300 \mathrm{hPa}$. Above $300 \mathrm{hPa}$ the plume strength decreases with altitude and reaches to $2.0 \%$ at $110 \mathrm{hPa}$. This transition of the variation of plume strength with altitude indicates the pressure levels where the Tibetan anticyclone is located. The existence of the Tibetan anticyclone at $110-200 \mathrm{hPa}$ facilitates the accumulation of $\mathrm{CH}_{4}$ and the formation of the $\mathrm{CH}_{4}$ plume at about $300-500 \mathrm{hPa}$. In levels above the Tibetan anticyclone (i.e. $110 \mathrm{hPa}$ ), the seasonal increase of $\mathrm{CH}_{4}$ mixing ratio from June to September is reduced significantly. From September to October, $\mathrm{CH}_{4}$ mixing ratio decreases significantly at all different levels, and the most significant decrease occurs at $200-300 \mathrm{hPa}$. This indicates the rapid disappearance of the $\mathrm{CH}_{4}$ plume in the middle to upper troposphere with the withdrawal of ASM. 


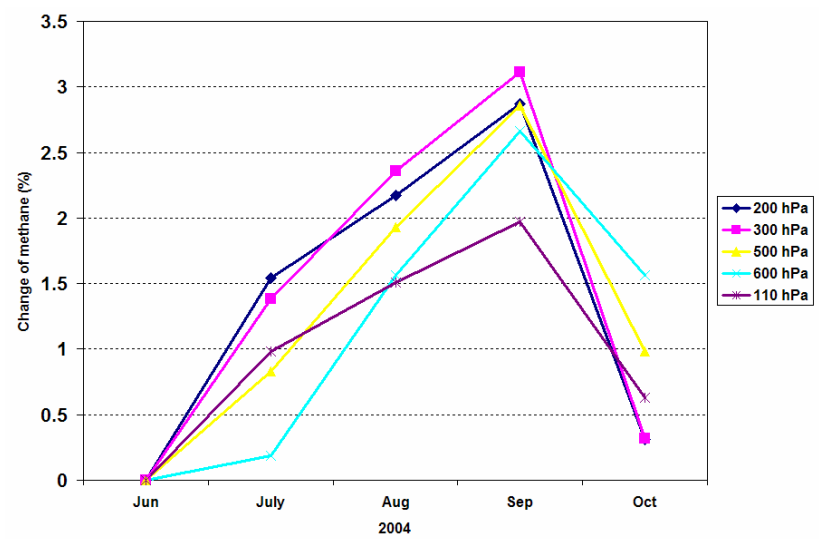

Fig. 6. Seasonal change of $\mathrm{CH}_{4}$ averaged in Region II at 5 pressure levels from July to October (relative to June). All data are from model simulation only.

Consistent with model simulations, the significant increase of $\mathrm{CH}_{4}$ in the middle to upper troposphere, as observed by AIRS, along with the increase in the lower stratosphere, as observed by HALOE measurement (Park et al., 2004), provide evidences for the transport of $\mathrm{CH}_{4}$ to the upper atmosphere. These results suggest that this transport of $\mathrm{CH}_{4}$ during the monsoon season may constitute an important emission pathway by which $\mathrm{CH}_{4}$ is transported from surface to stratosphere. Such a transport of $\mathrm{CH}_{4}$ as well as the transport of water vapor and other trace gases to stratosphere during the monsoon season may play an important role in atmospheric chemistry, and is worthy of further study.

3.4 Sensitivity of $\mathrm{CH}_{4}$ plume to $\mathrm{CH}_{4}$ emissions from southeast Asia

In order to investigate the relationship between the enhancement of tropospheric $\mathrm{CH}_{4}$ with surface emissions, a sensitivity study by model was performed by increasing $\mathrm{CH}_{4}$ emissions from Southeast Asia only. For simplification, we assumed an increase of $\mathrm{CH}_{4}$ emissions by $50 \%$ in Southeast Asia and re-run the model (2nd run). A comparison was made for the seasonal change of $\mathrm{CH}_{4}$ mixing ratio at $300 \mathrm{hPa}$ from July to October (relative to June) between these two runs. With the increase of surface emissions by $50 \%$ the "plume strength" increases from $3.1 \%$ to 5\% (Fig. 7). The results demonstrate that the larger the surface emission, the larger the $\mathrm{CH}_{4}$ enhancement in the middle to upper troposphere, so it is easier to detect from space.

We also calculated the difference of $\mathrm{CH}_{4}$ mixing ratio at $300 \mathrm{hPa}$ in these two runs. Here we used the $\mathrm{CH}_{4}$ mixing ratio from the 2nd run divided by the $\mathrm{CH}_{4}$ mixing ratio from the 1st run, that is, $100 \times \mathrm{CH}_{4}$ (2nd run)/ $\mathrm{CH}_{4}$ (1st run) -100 , for each month from June to September (Fig. 8). This difference represents the relative change of $\mathrm{CH}_{4}$ for each month corresponding to the increase of surface emissions. To account for

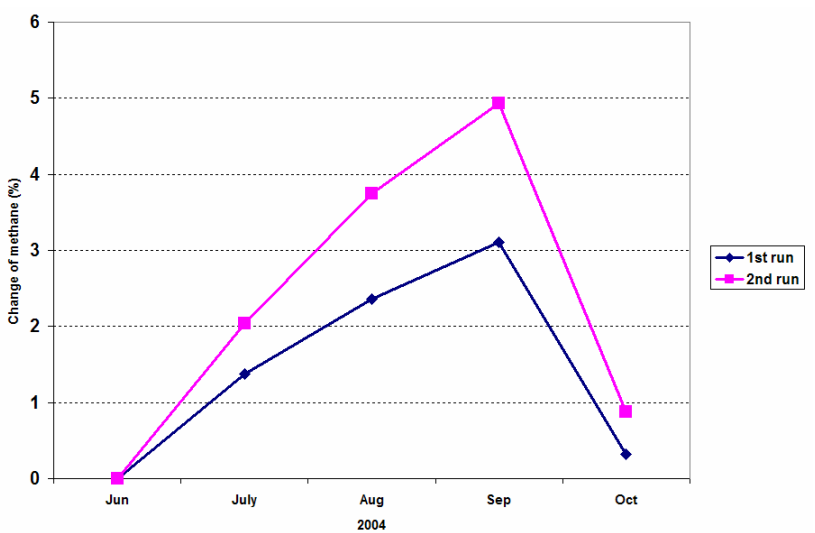

Fig. 7. Seasonal change of $\mathrm{CH}_{4}$ averaged in Region II from July to October (relative to June) for two different runs. $\mathrm{CH}_{4}$ emissions in Southeast Asia in the 2nd run are increased by $50 \%$ over those in the 1 st run. All data are from model simulation only.

the imbalance of $\mathrm{CH}_{4}$ sources and sinks in the 2nd run approximately, the difference of background concentration of $\mathrm{CH}_{4}$ mixing ratio (assumed to be the mean mixing ratio over ocean in the Southern Hemisphere ) between the 2nd run and the 1st run is removed from the data in the 2 nd run. As seen in Fig. 8, a significant increase of $\mathrm{CH}_{4}$ occurs in July, August and September, with the maximum occurring in September. The locations of the largest increase of $\mathrm{CH}_{4}$ are also similar to the locations of the $\mathrm{CH}_{4}$ plume (Fig. 1). With a 50\% increase of $\mathrm{CH}_{4}$ emissions in Southeast Asia, the monthly mean $\mathrm{CH}_{4}$ mixing ratio at $300 \mathrm{hPa}$ over Southeast Asia increases up to 4-5\% (or 70-80 ppbv) in September. However, the subtraction of the background difference of $\mathrm{CH}_{4}$ mixing ratio between the 2 nd and 1st runs may be inappropriate, because a strong local emission can lead to an enhancement of $\mathrm{CH}_{4}$ locally, and its mixing globally needs $1-2$ years. If we do not subtract this background difference from the 2nd run, the corresponding increase of the monthly mean $\mathrm{CH}_{4}$ mixing ratio at $300 \mathrm{hPa}$ over Southeast Asia will be up to $8-9 \%$ (or $140-150 \mathrm{ppbv}$ ) in September. In any event, the magnitude of such an increase of $\mathrm{CH}_{4}$ mixing ratio at $300 \mathrm{hPa}$, resulting from a 50\% increase of $\mathrm{CH}_{4}$ emissions in Southeast Asia, is significantly larger than the uncertainty of $0.5-1.6 \%$ in the AIRS retrieval. Therefore, the space-borne observation of the $\mathrm{CH}_{4}$ mixing ratio in the middle to upper troposphere over South Asia should be able to provide meaningful information about $\mathrm{CH}_{4}$ emissions in the summer. Under the assumption that the model performs well in simulating the transport and the chemical oxidation of $\mathrm{CH}_{4}$ in the atmosphere, the measurement of $\mathrm{CH}_{4}$ in the middle to upper troposphere by AIRS could potentially provide a constraint to the model to assess the Asian emission sources. 
June 2004

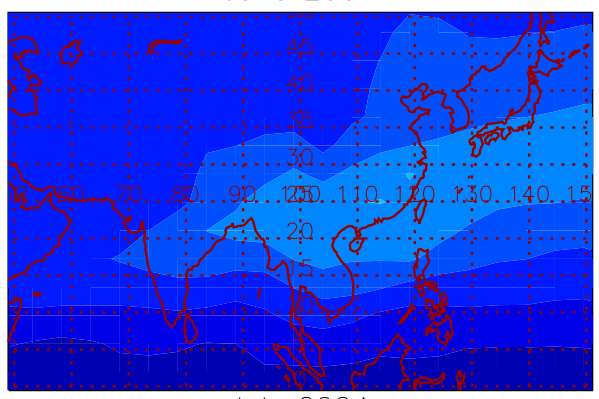

July 2004

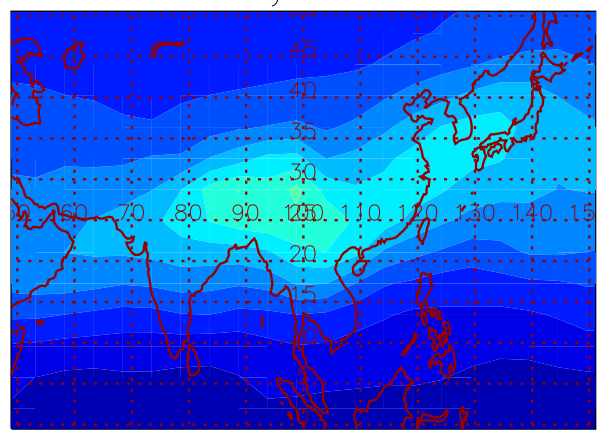

0

1

2

2

Fig. 8. Spatial distribution of the relative increase of $\mathrm{CH}_{4}$ mixing ratio at $300 \mathrm{hPa}$ corresponding to $50 \%$ increase of $\mathrm{CH}_{4}$ emissions over Southeast Asia (Region I, as marked in the box). The change of background concentration has been removed to account for the imbalance between the sources and sinks after $50 \%$ increase of $\mathrm{CH}_{4}$ emissions. All data are from model simulation only.

\section{Summary and conclusions}

Satellite retrievals of $\mathrm{CH}_{4}$ over South Asia using AIRS on EOS/Aqua from August 2003 to December 2007 along with TM3 model simulations have been presented and compared. They both showed similar enhancement of $\mathrm{CH}_{4}$ from June to September over Southeast Asia. The magnitude of $\mathrm{CH}_{4}$ enhancement at $300 \mathrm{hPa}$ is up to $100 \mathrm{ppbv}$ from AIRS retrievals (twice daily), with the maximum occurring in early September. The model simulations show the increase of the monthly mean from June to September is over 3\%. The rapid disappearance of the $\mathrm{CH}_{4}$ plume is observed in late September by AIRS, which is consistent with the withdrawal of monsoon. These results indicate that AIRS observations contain significant information about the vertical transport of $\mathrm{CH}_{4}$ from the boundary layer to the middle atmosphere, suggesting that the strong dynamic transport and the Tibetan anticyclone are two important factors in the formation of local maximum of $\mathrm{CH}_{4}$. Therefore, AIRS $\mathrm{CH}_{4}$ product may be valuable for studying the dissipation of the Tibetan anticyclone and the withdrawal of monsoon.

Consistent with other studies based on model simulations and/or observations, this observation of $\mathrm{CH}_{4}$ enhancement by AIRS provides additional evidence for the transport of chemical pollutants from the boundary layer to the upper troposphere over South Asia during the summer monsoon. Since the seasonal high $\mathrm{CH}_{4}$ emissions from rice paddies occurs almost simultaneously with the strong dynamic transport, this transport of $\mathrm{CH}_{4}$ may constitute an important emission pathway for $\mathrm{CH}_{4}$ to be transported from the surface to the upper troposphere and stratosphere. Its impact on the global $\mathrm{CH}_{4}$ budget, particularly on the stratospheric $\mathrm{CH}_{4}$, is worthy for more study.

Our model sensitivity study illustrated that in the monsoon region the surface source plays a major role in contributing to the $\mathrm{CH}_{4}$ enhancement in the mid to upper troposphere. For example, for an increase of $\mathrm{CH}_{4}$ emissions from Southeast Asia by $50 \%$, upper tropospheric $\mathrm{CH}_{4}$ increases by up to $8-9 \%$ (140-150 ppbv), or 4-5\% (70-80 ppbv) if considering the imbalance of sources and sinks, over Southeast Asia in September. Therefore, observation to the $\mathrm{CH}_{4}$ in the middle to upper troposphere and its seasonal change can provide valuable information of surface $\mathrm{CH}_{4}$ sources in these regions in the summer. Such observation becomes possible by using of space-borne hyperspectral measurements from AIRS and other operational infrared sounders, such as the Infrared Atmospheric Sounding Interferometer (IASI) onboard the METOP satellite. Use of these data will enable us to better understand the $\mathrm{CH}_{4}$ budget and study the global carbon cycle. However, more validation and improvement to 
AIRS/IASI retrieval of $\mathrm{CH}_{4}$ need to be accomplished before we can confidently apply them as a constraint in models aimed at obtaining accurate estimates of the Asian sources and sinks of $\mathrm{CH}_{4}$.

Acknowledgement. This research was supported by funding from NOAA Office of Application \& Research climate program. The views, opinions, and findings contained in this paper are those of the authors and should not be construed as an official National Oceanic and Atmospheric Administration or US Government position, policy, or decision.

Edited by: T. Röckmann

\section{References}

Aumann, H. H., Chahine, M. T., Gautier, C., Goldberg, M. D., Kalnay, E., McMillin, L. M., Revercomb, H., Rosenkranz, P. W., Smith, W. L., Staelin, D. H., Strow, L. L., and Susskind, J.: AIRS/AMSU/HSB on the aqua mission: Design, science objectives, data products, and processing systems, IEEE Transactions on Geoscience and Remote Sensing, 41, 253-264, 2003.

Cao, G., Xu, X., Long, R., Wang, Q., Qang, C., Du, Y., and Zhao, X.: Methane emissions by alpine plant communities in the Qinghai-Tibet Plateau, Bio. Lett., 4, 681-684, doi:10.1098/rsbl.2008.0373, 2008.

Clerbaux, C., Hadji-Lazaro, J., Turquety, S., Mégie, G., and Coheur, P.-F.: Trace gas measurements from infrared satellite for chemistry and climate applications, Atmos. Chem. Phys., 3, 14951508, 2003,

http://www.atmos-chem-phys.net/3/1495/2003/.

De Mazière, M., Vigouroux, C., Bernath, P. F., Baron, P., Blumenstock, T., Boone, C., Brogniez, C., Catoire, V., Coffey, M., Duchatelet, P., Griffith, D., Hannigan, J., Kasai, Y., Kramer, I., Jones, N., Mahieu, E., Manney, G. L., Piccolo, C., Randall, C., Robert, C., Senten, C., Strong, K., Taylor, J., Ttard, C., Walker, K. A., and Wood, S.: Validation of ACE-FTS v2.2 methane profiles from the upper troposphere to the lower mesosphere, Atmos. Chem. Phys., 8, 2421-2435, 2008,

http://www.atmos-chem-phys.net/8/2421/2008/.

Fasullo, J. and Webster, P. J.: A hydrological definition of indian monsoon onset and withdrawal, J. Climate, 16, 3200-3211, 2003.

Filipiak, M. J., Harwood, R. S., Jiang, J. H., Li, Q. B., Livesey, N. J., Manney, G. L., Read, W. G., Schwartz, M. J., Waters, J. W., and Wu, D. L.: Carbon monoxide measured by the EOS microwave limb sounder on Aura: First results, Geophys. Res. Lett., 32, L14825, doi:10.1029/2005GL02276, 2005.

Frankenberg, C., Meirink, J. F., van Weele, M., Platt, U., and Wagner, T.: Assessing methane emissions from global space-borne observations, Science, 308, 1010-1014, 2005.

Fu, R., Hu, Y., Wright, J. S., Jiang, J. H. , Dickinson, R. E. , Chen, M. , Filipiak, M. , Read, W. G., Waters, J. W., and Wu, D. L.: Short circuit of water vapor and polluted air to the global stratosphere by convective transport over the Tibetan Plateau, Proceedings of the National Academy of Sciences(PNAS), 103, 56645669, 2006.
Heimann, M. and KÖrner, S. : The global atmospheric tracer model TM3, Max Planck Institute of Biogeochemistry, Model description and user's manual, Release 3.8a, 2003.

Houweling, S., Rockmann, T., Aben, I., Keppler, F., Krol, M., Meirink, J. F., Dlugokencky, E. J., and Frankenberg, C.: Atmospheric constraints on global emissions of methane from plants, Geophys. Res. Lett., 33, L15821, doi:10.1029/2006GL026162, 2006.

Huang, Y., Zhang, W., Zheng, X. H., Li, J., and Yu, Y. Q.: Modeling methane emission from rice paddies with various agricultural practices, J. Geophys. Res.-Atmos., 109, D08113, doi:10.1029/2003JD004401. 2004.

Intergovernmental Panel on Climate Change: Climate Change 2007: The Physical Science Basis, Contribution of Working Group I to the Fourth Assessment Report of the Intergovernmental Panel on Climate Change, edited by: Solomon, S., Qin, D., Manning, M., Chen, Z., Marquis, M., Averyt, K. B., Tignor, M., and Miller, H. L., Cambridge University Press, 15 Cambridge, United Kingdom and New York, NY, USA, 500-590, 2007.

Jin, H., Wu, J., Cheng G., Nakano, T., and Sun, G.: Methane emissions from wetlands on the Qinghai-Tibet Plateau, Chinese Sci. Bull., 44(24), 2282-2286, 1999.

Kalnay, E., Kanamitsu, M., Kistler, R., Collins, W., Deaven, D., Gandin, L., Iredell, M., Saha, S., White, G., Woollen, J., Zhu, Y., Chelliah, M., Ebisuzaki, W., Higgins, W., Janowiak, J., Mo, K. C., Ropelewski, C., Wang, J., Leetmaa, A., Reynolds, R., Jenne, R., and Joseph, D.: The NCEP/NCAR 40-year reanalysis project, B. Am. Meteorol. Soc., 77, 437-471, 1996.

Kar, J., Bremer, H., Drummond, J. R., Rochon, Y. J., Jones, D. B. A., Nichitiu, F., Zou, J., Liu, J., Gille, J. C., Edwards, D. P., Deeter, M. N., Francis, G., Ziskin, D., and Warner, J.: Evidence of vertical transport of carbon monoxide from measurements of pollution in the troposphere (MOPITT), Geophys. Res. Lett., 31, L23105, doi:10.1029/2004GL021128, 2004.

Khalil, M. A. K., Rasmussen, R. A., Shearer, M. J., Dalluge, R. W., Ren, L. X., and Duan, C. L.: Measurements of methane emissions from rice fields in China, J. Geophys. Res.-Atmos., 103, 25 181-25 210, 1998.

Khalil, M. A. K. and Shearer, M. J.: Decreasing emissions of methane from rice agriculture, in Greenhouse Gases and Animal Agriculture: An Update, International Congress Series 1293, edited by: Soliva C. R., Takahasi, J., and Kreuzer, M., 33-41, Elsevier, Amsterdam, 2006.

Lawrence, M. G., Rasch, P. J., von Kuhlmann, R., Williams, J., Fischer, H., de Reus, M., Lelieveld, J., Crutzen, P. J., Schultz, M., Stier, P., Huntrieser, H., Heland, J., Stohl, A., Forster, C., Elbern, H., Jakobs, H., and Dickerson, R. R.: Global chemical weather forecasts for field campaign planning: predictions and observations of large-scale features during MINOS, CONTRACE, and INDOEX, Atmos. Chem. Phys., 3, 267-289, 2003, http://www.atmos-chem-phys.net/3/267/2003/.

Li, C., Qiu, J., Frolking, S. , Xiao, X., Salas, W., Moore III, B., Boles, S., Huang, Y., and Sass, R.: Reduced methane emissions from large-scale changes in water management of China's rice paddies during 1980-2000, Geophys. Res. Lett., 29(20), 1972, doi:10.1029/2002GL015370, 2002,.

Li, Q. B., Jacob, D. J., Logan, J. A., Bey, I., Yantosca, R. M., Liu, H. Y., Martin, R. V., Fiore, A. M., Field, B. D., Duncan, B. N., and Thouret, V.: A tropospheric ozone maximum over the middle 
east, Geophys. Res. Lett., 28, 3235-3238, 2001.

Li, Q. B., Jiang, J. H., Wu, D. L., Read, W. G., Livesey, N. J., Waters, J. W., Zhang, Y. S., Wang, B., Filipiak, M. J., Davis, C. P., Turquety, S., Wu, S. L., Park, R. J., Yantosca, R. M., and Jacob, D. J.: Convective outflow of south asian pollution: A global ctm simulation compared with EOS MLS observations, Geophys. Res. Lett., 32, L14826, doi:10.1029/2005GL022762, 2005.

Liu, Y., Li, W. L., Zhou, X. J., Isaksen, I. S. A., Sundet, J. K., and He, J. H.: The possible influences of the increasing anthropogenic emissions in india on tropospheric ozone and $\mathrm{OH}, \mathrm{Adv}$. Atmos. Sci., 20, 968-977, 2003.

Maddy, E. S. and Barnet, C. D.: Vertical resolution estimates in Version 5 of AIRS operational retrievals, IEEE T. Geosci. Remote, 46, 8, 2008.

Nassar, R., Bernath, P.F., Boone, C. D., Manney, G. L., McLeod, S. D., Rinsland, C. P., Skelton, R., and Walker, K. A., Stratospheric abundances of water and methane based on ACE-FTS measurements, Geophys. Res. Lett., 32, L15S04, doi:10.1029/2005GL022383, 2005.

Park, M., Randel, W. J., Kinnison, D. E., Garcia, R. R., and Choi, W.: Seasonal variation of methane, water vapor, and nitrogen oxides near the tropopause: Satellite observations and model simulations, J. Geophys. Res.-Atmos., 109, D03302, doi:10.1029/2003JD003706, 2004.

Payan, S., Camy-Peyret, C., Oelhaf, H., Wetzel, G., Maucher, G., Keim, C., Pirre, M., Huret, N., Engel, A., Volk, M. C., Kuellmann, H., Kuttippurath, J., Cortesi, U., Bianchini, G., Mencaraglia, F., Raspollini, P., Redaelli, G., Vigouroux, C., De Mazire, M., Mikuteit, S., Blumenstock, T., Velazco, V., Notholt, J., Mahieu, M., Duchatelet, P., Smale, D., Wood, S., Jones, N., Piccolo, C., Payne, V., Bracher, A., Glatthor, N., Stiller, G., Grunow, K., Jeseck, P., Te, Y., Pfeilsticker, K., and Butz, A.: Validation and data characteristics of methane and nitrous oxide profiles observed by MIPAS and processed with Version 4.61 algorithm, Atmos. Chem. Phys. Discuss., 7, 18043-18111, 2007, http://www.atmos-chem-phys-discuss.net/7/18043/2007/.
Randel, W. J. and Park, M.: Deep convective influence on the asian summer monsoon anticyclone and associated tracer variability observed with atmospheric infrared sounder (AIRS), J. Geophys. Res.-Atmos., 111, D12314, doi:10.1029/2005JD006490, 2006.

Rodgers, C. D.: Inverse Methods for Atmospheric Sounding, World Sci., Hackensack, N. J., 2000.

Strow, L. L., Hannon, S. E., De Souza-Machado, S., Motteler, H. E., and Tobin, D.: An overview of the airs radiative transfer model, IEEE Transactions on Geoscience and Remote Sensing, 41, 303313, 2003.

Susskind, J., Barnet, C. D., and Blaisdell, J. M.: Retrieval of atmospheric and surface parameters from AIRS/AMSU/HSB data in the presence of clouds, IEEE Transactions on Geoscience and Remote Sensing, 41, 390-409, 2003.

Taniguchi, K. and Koike, T.: Seasonal Variation of Cloud Activity and Atmospheric Profiles over the Eastern Part of the Tibetan Plateau, J. Geophys. Res., 113, D10104, doi:10.1029/2007JD009321, 2008.

Xiong, X., Barnet, C. D., Maddy, E., Sweeney, C., Liu, X., Zhou, L., and Goldberg, M.: Characterization and Validation of Methane Products from the Atmospheric Infrared Sounder (AIRS), J. Geophys. Res., 113, G00A01, doi:10.1029/2007JG000500, 2008.

Ye, D. Z. and Wu, G. X.: The role of the heat source of the tibetan plateau in the general circulation, Meteorol. Atmos. Phys., 67, 181-198, 1998.

Zhou, L. X. , Worthy, D. E. J., Land, P. M., Ernst, M. K., Zhang, X. C., Wen, Y. P., and Li, J. L.: Ten years of atmospheric methane observations at a high elevation site in Western China, Atmos. Environ., 38, 7041-7054, 2004. 